\title{
Punching Shear Strength of Reinforced Concrete Slabs without Transverse Reinforcement
}

\author{
by Aurelio Muttoni
}

\begin{abstract}
A mechanical explanation of the phenomenon of punching shear in slabs without transverse reinforcement is presented on the basis of the opening of a critical shear crack. It leads to the formulation of a new failure criterion for punching shear based on the rotation of a slab. This criterion correctly describes punching shear failures observed in experimental testing, even in slabs with low reinforcement ratios. Its application requires the knowledge of the load-rotation relationship of the slab, for which a simple mechanical model is proposed. The resulting approach is shown to give better results than current design codes, with a very low coefficient of variation $(\mathrm{COV})$. Parametric studies demonstrate that it correctly predicts several aspects of punching shear previously observed in testing as size effect (decreasing nominal shear strength with increasing size of the member). Accounting for the proposed failure criterion and load-rotation relationship of the slab, the punching shear strength of a flat slab is shown to depend on the span of the slab, rather than on its thickness as often proposed.
\end{abstract}

Keywords: critical shear crack; interior slab-column connection; punching shear; two-way shear.

\section{INTRODUCTION}

Reinforced concrete slabs on columns were initially developed in the U.S. and Europe at the beginning of the 20th century. 1,2 Their designs typically included large mushroom-shaped column capitals to facilitate the local introduction of forces from the slab to the column. In the 1950s, flat slabs without capitals started to become prevalent. Because of their simplicity, both for construction and for use (simple formwork and reinforcement, flat soffit allowing an easy placement of equipment, and installation underneath the slab), they have become very common for medium height residential and office buildings as well as for parking garages. The design of flat slabs is mostly governed by serviceability conditions on the one side (with relatively large deflections in service) and by the ultimate limit state of punching shear (also called two-way shear) on the other side. These two criteria typically lead to the selection of the appropriate slab thickness.

Punching shear has been the object of an intense experimental effort since the 1950s. In most cases, the phenomenon is investigated by considering an isolated slab element. This element typically represents the surface of the slab surrounding a column and is delimited by the line of contraflexure for radial moments, which are zero at a distance $r_{s} \approx 0.22 L$ (according to a linear-elastic estimate), where $L$ is the axis-to-axis spacing of the columns. In recent years, several state-of-the-art reports and synthesis papers have been published on this topic. ${ }^{3-5}$

Most design codes base their verifications on a critical section, with the punching shear strength of slabs without shear reinforcement defined as a function of the concrete compressive strength and often of the reinforcement ratio.
Some codes also account for size effect, membrane effect, or the ratio of column size to the depth of the slab. Equation (1) shows the ACI $318-05^{6}$ expression for square or circular columns of moderate dimensions relative to the thickness of the slab

$$
\begin{gathered}
V_{R}=\frac{1}{3} b_{0} d \sqrt{f_{c}^{\prime}} \text { (SI units: MPa, mm) } \\
V_{R}=4 b_{0} d \sqrt{f_{c}^{\prime}} \text { (U.S. customary units: psi, in.) }
\end{gathered}
$$

where $d$ is the average flexural depth of the slab, $b_{0}$ is the perimeter of the critical section located $d / 2$ from the face of the column, and $f_{c}{ }^{\prime}$ is the specified concrete compressive strength.

The current version of Eurocode $2^{7}$ also includes a formulation for estimating the punching shear strength of slabs

$$
\begin{gathered}
V_{R}=0.18 b_{0} d \xi\left(100 \rho_{l} f_{c}^{\prime}\right)^{\frac{1}{3}} \text { (SI units: MPa, mm) } \\
V_{R}=5.0 b_{0} d \xi\left(100 \rho_{l} f_{c}^{\prime}\right)^{\frac{1}{3}} \text { (U.S. customary units: psi, in.) }
\end{gathered}
$$

where $b_{0}$ is the control perimeter located $2 d$ from the face of the column, $\rho_{l}$ accounts for the bending reinforcement ratio (with a maximum value of 0.02 ) and $\xi$ is a factor accounting for size effect defined by the following expression

$$
\xi=1+\sqrt{\frac{200 \mathrm{~mm}}{d}}=1+\sqrt{\frac{7.87 \mathrm{in} .}{d}} \leq 2.0
$$

In the early 1960 s, Kinnunen and Nylander ${ }^{8}$ tested a series of slabs in punching, varying amongst other parameters the amount of flexural reinforcement in the slab (refer to Fig. 1). The following observations can be made from the load-rotation relationships of the tests:

- For low reinforcement ratios (test with $\rho=0.5 \%$ ), the observed behavior is ductile, with yielding of the entire flexural reinforcement, as illustrated by the horizontal asymptote of the load-rotation curve. In this case, the strength of the slab is limited by its flexural capacity and punching occurs only after large plastic deformations. The punching failure at the end of the plastic plateau remains brittle and leads to a sudden drop in strength;

ACI Structural Journal, V. 105, No. 4, July-August 2008

MS No. S-2006-478 received December 11, 2006, and reviewed under Institute publication policies. Copyright (C) 2008, American Concrete Institute. All rights reserved, including the making of copies unless permission is obtained from the copyright proprietors. Pertinent discussion including author's closure, if any, will be published in the MayJune 2009 ACI Structural Journal if the discussion is received by January 1, 2009. 
ACI member Aurelio Muttoni is a Professor and Head of the Structural Concrete Laboratory at the Ecole Polytechnique Fédérale de Lausanne (EPFL), Lausanne, Switzerland. He received his diploma and PhD in civil engineering from the Swiss Federal Institute of Technology, Zurich, Switzerland, in 1982 and 1989, respectively. His research interests include the theoretical basis of the design of reinforced concrete structures, shear and punching shear, fiber-reinforced high-strength concrete, soilstructure interaction, and the conceptual design of bridges.

- For intermediate reinforcement ratios (tests with $\rho=$ $1.0 \% / 0.5 \%$ and $1.0 \%$ ), some yielding of the reinforcement is present in the immediate vicinity of the column, but punching occurs before yielding of the entire slab reinforcement. In this case, the strength of the slab is lower than its flexural capacity;

- $\quad$ For large reinforcement ratios (test with $\rho=2.1 \% / 1.0 \%$ ), punching occurs before any yielding of the reinforcement takes place, in a very brittle manner. In this case, the strength of the slab is significantly lower than its flexural capacity;

- Increasing the reinforcement ratio increases the punching capacity, but strongly decreases the deformation capacity of the slab; and

- The ACI design equation is also plotted in the figure. It predicts a constant strength independent from the reinforcement ratio. As observed by Alexander and Hawkins, ${ }^{9}$ Eq. (1) is basically a design equation; as such, it does not account for the effect of the flexural reinforcement.

On the basis of their test results, Kinnunen and Nylander ${ }^{8}$ developed a rational theory for the estimation of the punching shear strength in the early 1960s based on the assumption that the punching strength is reached for a given critical rotation $\psi$. This rotation was calculated by simplifying the kinematics of the slab and assuming a bilinear moment-curvature relationship. Thus far, this proposal remains one of the best models for the phenomenon of punching. Recently, some improvements were proposed by Hallgren ${ }^{10}$ and Broms ${ }^{11}$ to account for size effects and highstrength concrete. While very elegant and leading to good results, this model was never directly included in codes of practice because its application is too complex. It served as a basis, however, for the Swedish and Swiss design codes of the 1960s.

\section{RESEARCH SIGNIFICANCE}

Rational models and design formulas for punching shear, or two-way shear, are based on the results of experimental tests performed mostly on thin slabs $(d=0.1$ to $0.2 \mathrm{~m}$ [ 4 to 8 in.]). Design codes, however, are generally also applicable to thick slabs and footings ( $0.4 \mathrm{~m}$ [16 in.] and more). The few available tests performed on thick slabs exhibit a notable size effect. As a consequence, there is a need for a rational model correctly describing punching shear and accounting for size effect (defined as decreasing nominal shear strength with increasing size of the member).

In this paper, a new failure criterion for punching shear based on the critical shear crack theory is presented. This criterion describes the relationship between the punching shear strength of a slab and its rotation at failure, it is consistent with the works of Kinnunen and Nylander ${ }^{8}$ and it accounts for size effect. The resulting equations are presented in a code-friendly formulation.

\section{FAILURE CRITERION BASED ON CRITICAL SHEAR CRACK THEORY \\ Critical shear crack theory}

As shown in Fig. 1, the punching shear strength decreases with increasing rotation of the slab. This has been explained by Muttoni and Schwartz ${ }^{12}$ as follows: the shear strength is reduced by the presence of a critical shear crack that propagates through the slab into the inclined compression strut carrying the shear force to the column (Fig. 2(b)). Some evidences supporting the role of the shear critical crack in the punching shear strength are detailed in the following:

1. It has been shown experimentally ${ }^{8,13}$ that the radial compressive strain in the soffit of the slab near the column, after reaching a maximum for a certain load level, begins to decrease (Fig. 2(d)). Shortly before punching, tensile strains may be observed. This phenomenon can be explained by the development of an elbow-shaped strut with a horizontal tensile member along the soffit due to the development of the critical shear crack ${ }^{12}$ (Fig. 2(c)). A similar phenomenon has been observed in beams without shear reinforcement ${ }^{12}$; and

2. Experimental results by Bollinger ${ }^{14}$ also confirm the role of the critical shear crack in the punching strength of slabs. The tested slab shown in Fig. 3(b) was reinforced by concentric rings placed at the boundary of the slab element only. With this particular reinforcement layout, only radial cracks developed and the formation of circular cracks in the critical region was avoided. Thus, the punching shear strength of this test was significantly larger than that of a similar slab with an additional ring in the critical region (Fig. 3(c)). For this test, the presence of an additional ring in the vicinity of the critical region initiated the development of a crack in that region, with a subsequent reduction of the punching shear strength of approximately $43 \%$.

\section{Punching shear strength as function of slab rotation}

The opening of the critical shear crack reduces the strength of the inclined concrete compression strut carrying shear and eventually leads to the punching shear failure. According to Muttoni and Schwartz, ${ }^{12}$ the width of the critical crack can be assumed to be proportional to the product $\psi d$ (Fig. 4), leading to a semi-empirical failure criterion formulated in 1991 as

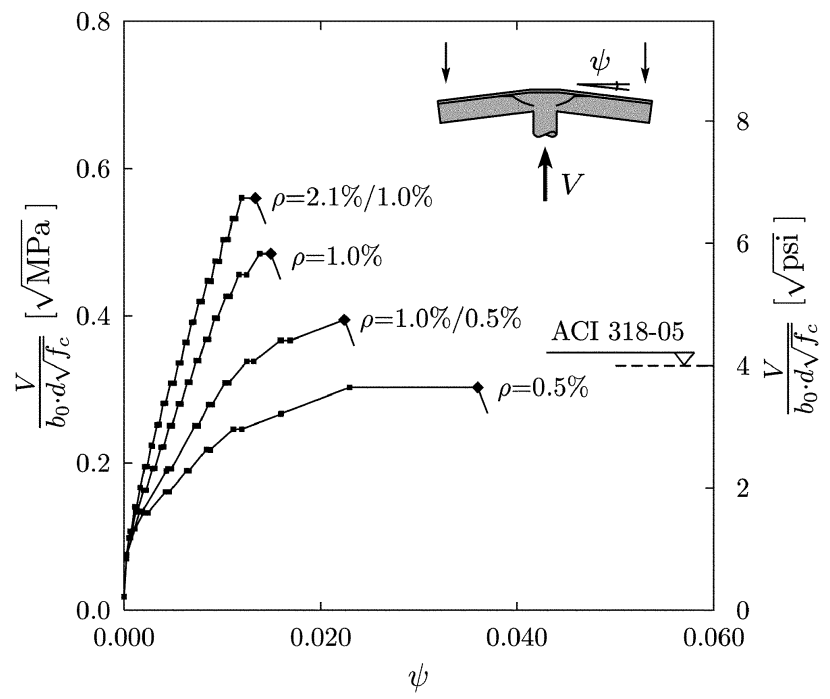

Fig. 1-Plots of load-rotation curves for tests by Kinnunen and Nylander ${ }^{8}$ (geometric and mechanical parameters of tests defined in Fig. 8). 

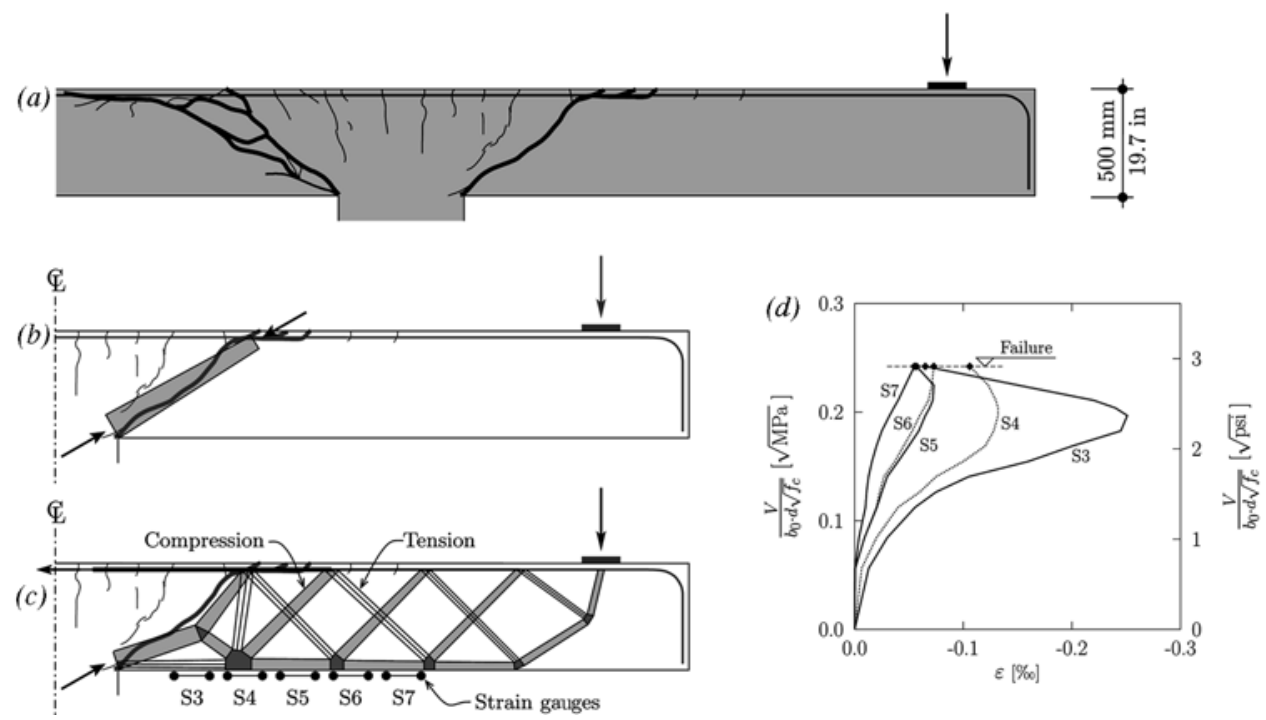

Fig. 2-Test PG-3 by Guandalini and Muttoni ${ }^{13}$ (geometric and mechanical parameters of test defined in Fig. 9): (a) cracking pattern of slab after failure; (b) theoretical strut developing across the critical shear crack; (c) elbow-shaped strut; and (d) plots of measured radial strains in soffit of slab as function of applied load.

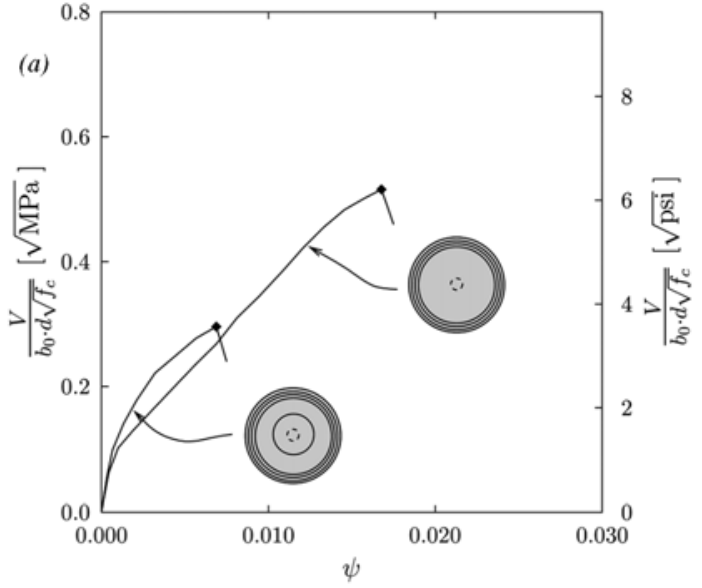

(b)

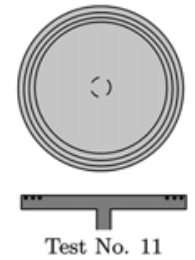

$V_{\text {test }}=76.1 \mathrm{kN}(17.0 \mathrm{kips})$

3 reinforcement rings $d_{b} 10$ (3 \# 3) (c)

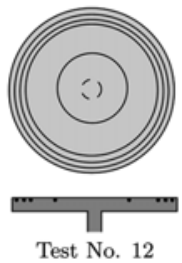

$V_{\text {test }}=44.0 \mathrm{kN}(9.83 \mathrm{kips})$

3 reinf. rings $d_{b} 10+1$ reinf. ring $d_{b} 12$

$(3 \# 3+1 \# 4)$

Fig. 3-Tests by Bollinger ${ }^{14}$ with ring reinforcements, effect of additional reinforcement in vicinity of critical shear crack on load-carrying capacity: (a) test results; and (b) and (c) reinforcement layout of Specimens 11 and 12.

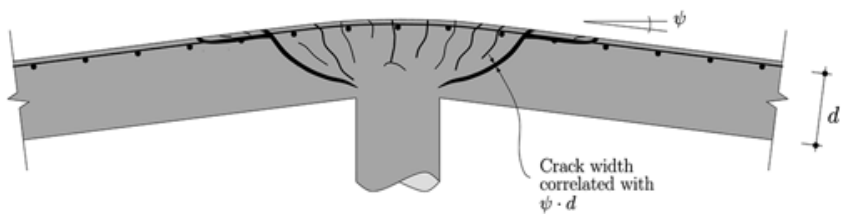

Fig. 4-Correlation between opening of critical shear crack, thickness of slab, and rotation $\psi$.

$$
\begin{aligned}
& \left.\frac{V_{E}}{b_{0} d \sqrt[3]{f_{c}}}=\frac{1}{1+\left(\frac{\psi d}{4 \mathrm{~mm}}\right)^{2}} \quad \text { (SI units; } \mathrm{N}, \mathrm{mm}\right) \\
& \frac{V_{R}}{b_{0} d \sqrt[3]{f_{c}}}=\frac{28}{1+\left(\frac{\psi d}{0.16 \text { in. }}\right)^{2}} \text { U.S. customary units; psi, in.) }
\end{aligned}
$$

The amount of shear that can be transferred across the critical shear crack depends on the roughness of the crack, which in its turn is a function of the maximum aggregate size. According to Walraven ${ }^{15}$ and Vecchio and Collins, ${ }^{16}$ the roughness of the critical crack and its capacity to carry the shear forces can be accounted for by dividing the nominal crack width $\psi d$ by the quantity $\left(d_{g 0}+d_{g}\right)$, where $d_{g}$ is the maximum aggregate size, and $d_{g 0}$ is a reference size equal to $16 \mathrm{~mm}$ (0.63 in.). It should be noted that the value of $d_{g}$ has to be set to zero for lightweight aggregate concrete to account for cracks developing through aggregates. On that basis, in 2003 Muttoni $^{17}$ proposed an improved formulation for the failure criterion

$$
\begin{gathered}
\left.\frac{V_{R}}{b_{0} d \sqrt{f_{c}}}=\frac{3 / 4}{1+15 \frac{\psi d}{d_{g 0}+d_{g}}} \text { (SI units: } \mathrm{N}, \mathrm{mm}\right) \\
\frac{V_{R}}{b_{0} d \sqrt{f_{c}}}=\frac{9}{1+15 \frac{\psi d}{d_{g 0}+d_{g}}} \text { (U.S. customary units: psi, in.) }
\end{gathered}
$$

Figure 5 compares the results obtained with Eq. (5) to the results of 99 punching tests from the literature, for which Table 1 provides additional information. In this figure, the slab rotation was either obtained from direct measurements or calculated by the author from the measured deflection, assuming a conical deformation of the slab outside the 
column region. In cases where different reinforcement ratios were placed along orthogonal directions, the maximum rotation of the slab was considered. The rotation $\psi$ is multiplied by the factor $d /\left(d_{g 0}+d_{g}\right)$ to cancel the effects of slab thickness and aggregate size. Tests in which punching shear failure occurred after reaching the flexural strength $V_{\text {flex }}$ are also considered (shown as empty squares in the figure).

The expression provided in ACI $318-05^{6}$ is also plotted in Fig. 5. It can be noted that for small values of $\psi d /\left(d_{g 0}+d_{g}\right)$, the code gives rather conservative results. This is also the area of the plot in which the majority of the tests are located. For large values of $\psi d /\left(d_{g 0}+d_{g}\right)$, however, the ACI equation predicts significantly larger punching shear strengths than effectively observed in tests. This fact can be traced back to two causes:

1. When the ACI formula was originally proposed in the early $1960 \mathrm{~s},{ }^{9,19}$ only tests with relatively small effective depths were available and the influence of size effect was thus not apparent; and

2. Tests in which punching failure occurred after reaching the flexural strength but with limited rotation capacity are considered in the comparison (empty squares).

\section{LOAD-ROTATION RELATIONSHIP}

Comparing Fig. 1 and 5, it is clear that the punching failure occurs at the intersection of the load-rotation curve of the slab with the failure criterion. To enable a calculation of the punching shear strength according to Eq. (5), the relationship between the rotation $\psi$ and the applied load $V$ needs to be known. In the most general case, the load-rotation relationship can be obtained by a nonlinear numerical simulation of the flexural behavior of the slab, using, for example, a nonlinear finite element code. In axisymmetric cases, a numerical integration of the moment-curvature relationship can be performed directly. ${ }^{26}$ This allows to account for bending moment redistributions in flat slabs and to account for the increase on punching shear strength due to in-plane confinement given by the flat slab in the portions of the slab near columns. ${ }^{26}$

The axisymmetric case of an isolated slab element can also be treated analytically after some simplifications. As already described, the tangential cracks and the radial curvature are

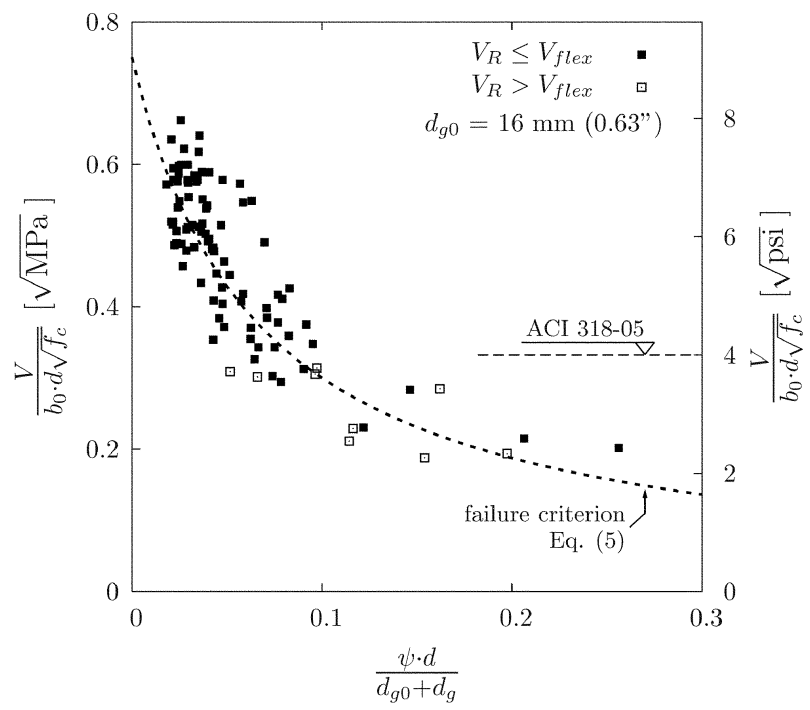

Fig. 5-Failure criterion: punching shear strength as function of width of critical shear crack compared with 99 experimental results and ACI 318-056 design equation, refer to details of test series in Table 1. concentrated in the vicinity of the column. Outside the critical shear crack, located at a radius $r_{0}$ (assumed to be at a distance $d$ from the face of the column), the radial moment, and thus the radial curvature, decreases rapidly as shown in Fig. 6(d) and (e). Consequently, it can be assumed that the corresponding slab portion deforms following a conical shape with a constant slab rotation $\psi$ (Fig. 6(a)).

In the region inside the radius $r_{0}$, the radial moment is considered constant because the equilibrium of forces is performed along cross sections defined by the shape of the inclined cracks (Fig. 6(b) and (c)), where the force in the reinforcement remains constant (due to the fact that the shear force is introduced in the column by an inclined strut developing from outside the shear critical crack (Fig. 2(b) and (c)).

The full development of the expressions for the load-rotation relationship of the slab is given in Appendix 1. ${ }^{*}$ Considering a quadrilinear moment-curvature relationship for the reinforced concrete section (Fig. 7), the following expression results

$V=\frac{2 \pi}{r_{q}-r_{c}}\left(\begin{array}{c}-m_{r} r_{0}+m_{R}\left\langle r_{y}-r_{0}\right\rangle+E I_{1} \psi\left\langle\ln \left(r_{1}\right)-\ln \left(r_{y}\right)\right\rangle+ \\ E I_{1} \chi_{T S}\left\langle r_{1}-r_{y}\right\rangle+m_{c r}\left\langle r_{c r}-r_{1}\right\rangle+E I_{0} \psi\left\langle\ln \left(r_{s}\right)-\ln \left(r_{c r}\right)\right\rangle\end{array}\right)(6)$

where $m_{r}$ is the radial moment per unit length acting in the slab portion at $r=r_{0}$ and the operator $\langle\mathrm{x}\rangle$ is $x$ for $x \geq 0$ and 0 for $x<0$.

A simpler moment-curvature relationship can be adopted by neglecting the tensile strength of concrete $f_{c t}$ and the effect of tension stiffening, leading to a bilinear relationship similar to that of Kinnunen and Nylander, ${ }^{8}$ shown as a dotted line in Fig. 7. The analytical expression describing the loadrotation relationship is thus

Table 1-Test series considered in present study and comparison with proposed failure criterion

\begin{tabular}{|c|c|c|c|c|}
\hline \multirow[b]{2}{*}{ Reference (year) } & \multirow[b]{2}{*}{$d, \mathrm{~mm}$ (in.) } & \multirow[b]{2}{*}{ No. } & \multicolumn{2}{|c|}{$\begin{array}{c}\text { Failure criterion } \\
V_{\text {test }} / V_{t h}\end{array}$} \\
\hline & & & Average & $\mathrm{COV}$ \\
\hline \multicolumn{5}{|c|}{ Tests with same bending reinforcement ratio along orthogonal directions } \\
\hline Elstner and Hognestad ${ }^{18}(1956)$ & $115(4.52)$ & 22 & 0.98 & 0.14 \\
\hline Kinnunen and Nylander ${ }^{8}(1960)$ & $122(4.80)$ & 12 & 1.05 & 0.11 \\
\hline $\operatorname{Moe}^{19}(1961)$ & $114(4.48)$ & 9 & 1.13 & 0.16 \\
\hline Schäfers $^{20}(1984)$ & $\begin{array}{c}113 \text { to } 170 \\
(4.45 \text { to } 6.69)\end{array}$ & 4 & 1.03 & 0.20 \\
\hline Tolf $^{21}(1988)$ & $\begin{array}{c}98 \text { to } 200 \\
\text { (3.86 to } 7.87)\end{array}$ & 8 & 1.06 & 0.15 \\
\hline Hassanzadeh $^{22}(1996)$ & $200(7.87)$ & 3 & 0.99 & 0.17 \\
\hline Hallgren ${ }^{10}(1996)$ & $199(7.83)$ & 7 & 0.98 & 0.25 \\
\hline Ramdane $^{23}(1996)$ & $98(3.86)$ & 12 & 1.10 & 0.16 \\
\hline Guandalini and Muttoni ${ }^{13}$ (2004) & \begin{tabular}{|c|}
96 to 464 \\
(3.78 to 18.2$)$ \\
\end{tabular} & 10 & 1.11 & 0.22 \\
\hline \multicolumn{2}{|l|}{$\Sigma$} & 87 & 1.05 & 0.16 \\
\hline \multicolumn{5}{|c|}{ Tests with different bending reinforcement ratio along orthogonal directions } \\
\hline Nylander and Sundquist $^{24}$ (1972) & \begin{tabular}{|c|}
95 to 202 \\
(3.74 to 7.95$)$ \\
\end{tabular} & 11 & 1.04 & 0.09 \\
\hline Kinnunen et al. $^{25}(1980)$ & $673(26.5)$ & 1 & 0.85 & - \\
\hline \multicolumn{2}{|l|}{$\Sigma$} & 12 & 1.03 & 0.10 \\
\hline
\end{tabular}

Note: $\mathrm{COV}=$ coefficient of variation.

\footnotetext{
${ }^{*}$ The Appendixes are available at www.concrete.org in PDF format as an addendum to the published paper. It is also available in hard copy from ACI headquarters for a fee equal to the cost of reproduction plus handling at the time of the request.
} 
$V=\frac{2 \pi}{r_{q}-r_{c}} E I_{1} \psi\left(1+\ln \frac{r_{s}}{r_{0}}\right)$ for $r_{y} \leq r_{0}($ elastic regime $)(7 \mathrm{a})$

$V=\frac{2 \pi}{r_{q}-r_{c}} E I_{1} \psi\left(1+\ln \frac{r_{s}}{r_{y}}\right)$ for $r_{0} \leq r_{y} \leq r_{s}$ (elasto-plastic regime)

The flexural strength of the slab specimen is reached when the radius of the yielded zone $\left(r_{y}\right)$ equals the radius of the slab $r_{s}$. In this case $\left(r_{y}=r_{s}=r_{1}=r_{c r}\right.$, and $\left.-m_{r}=m_{R}\right)$, Eq. (6) yields

$$
V_{\text {flex }}=2 \pi m_{R} \frac{r_{s}}{r_{q}-r_{c}} \text { (plastic regime) }
$$

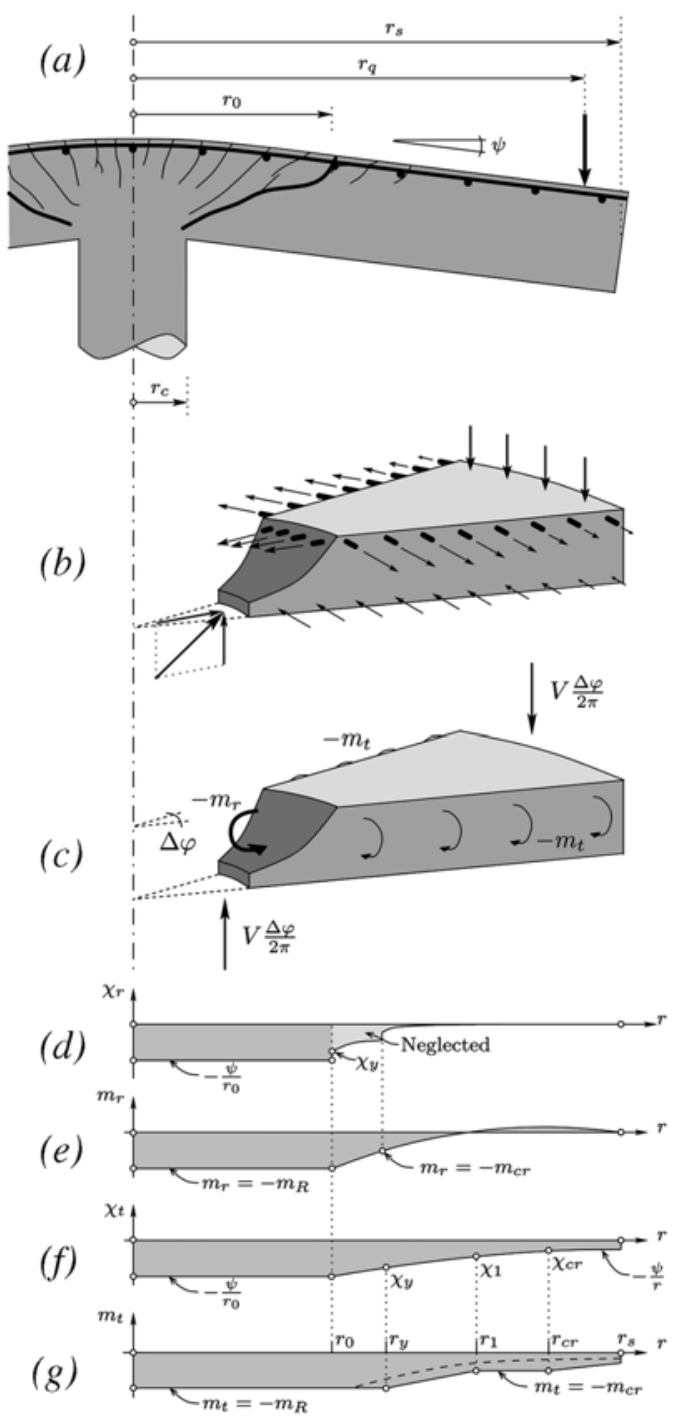

Fig. 6-Assumed behavior for axisymmetric slab: (a) geometrical parameters and rotation of slab; (b) forces in concrete and in reinforcement acting on slab sector; (c) internal forces acting on slab sector; (d) distribution of radial curvature; (e) distribution of radial moment; $(f)$ distribution of tangential curvature; and $(g)$ distribution of tangential moments for quadrilinear moment-curvature relationship (shaded area) and for bilinear moment-curvature relationship (dashed line).
Figure 8 shows a comparison of the proposed solutions with the previously described tests by Kinnunen and Nylander ${ }^{8}$ (Fig. 1). The solid curves represent the solution

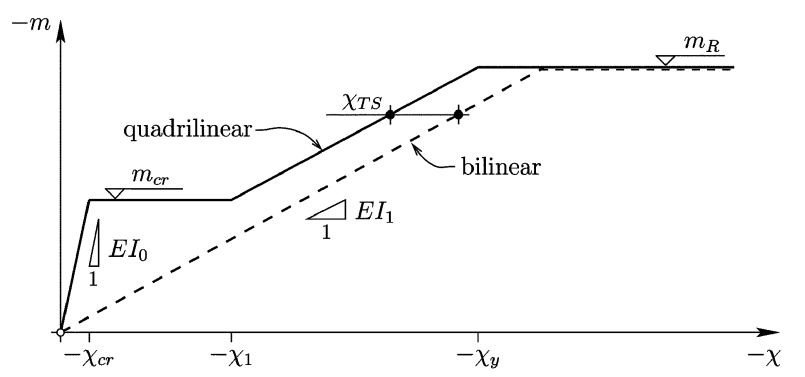

Fig. 7-Moment-curvature relationships: bilinear and quadrilinear laws.

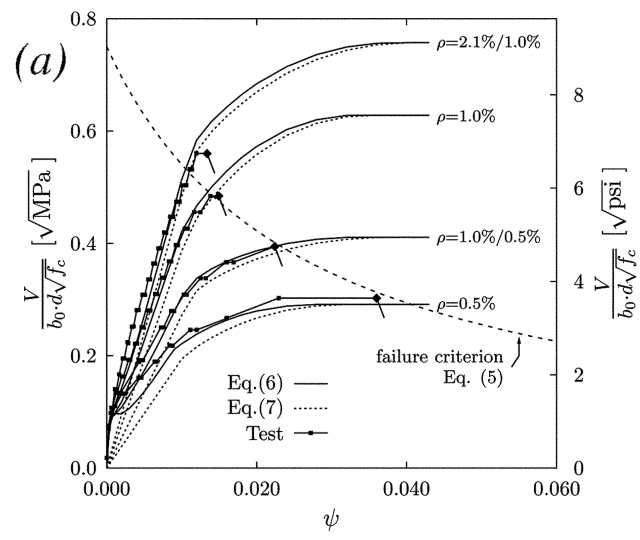

(b)

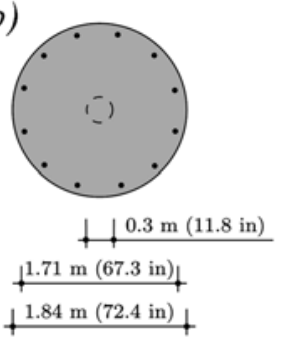

(c)
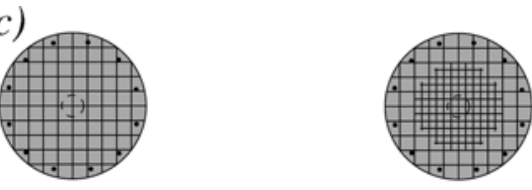

IA $30 \mathrm{~d}-32$

$f_{c}=26.8 \mathrm{MPa}(3900 \mathrm{psi})$

IA30e-34

$f_{c}=451 \mathrm{MPa}(64900 \mathrm{psi})$

$d=123 \mathrm{~mm}(4.84 \mathrm{in})$

$\rho=0.5 \%$

$d_{g}=32 \mathrm{~mm}(1.26 \mathrm{in})$

$f_{c}=27.9 \mathrm{MPa}(4000 \mathrm{psi})$

$f_{y}=461 \mathrm{MPa}(66800 \mathrm{psi})$

$d=120 \mathrm{~mm}(4.72 \mathrm{in})$

$\rho_{\min }=0.5 \%$

$\rho_{\max }=1.0 \%$

$d_{g}=32 \mathrm{~mm}(1.26 \mathrm{in})$
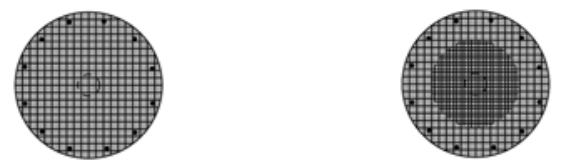

IA30a-25

$f_{c}=25.6 \mathrm{MPa}(3700 \mathrm{psi})$

$f_{y}=451 \mathrm{MPa}(65300 \mathrm{psi})$

$d=124 \mathrm{~mm}(4.88 \mathrm{in})$

$\rho=1.0 \%$

$d_{g}=32 \mathrm{~mm}(1.26 \mathrm{in})$

LA $30 \mathrm{c}-30$

$f_{c}=30.6 \mathrm{MPa}(4400 \mathrm{psi})$

$f_{y}=435 \mathrm{MPa}(63000 \mathrm{psi})$

$d=120 \mathrm{~mm}(4.72 \mathrm{in})$

$\rho_{\min }=1.0 \%$

$\rho_{\max }=2.1 \%$

$d_{g}=32 \mathrm{~mm}(1.26 \mathrm{in})$

Fig. 8-Tests by Kinnunen and Nylander ${ }^{8}$ : (a) comparison of load-rotation curves for tests and for proposed analytical expressions (Eq. (6) and (7)); (b) dimensions of specimens; and $(c)$ mechanical parameters. 
with a quadrilinear moment-curvature relationship of Eq. (6), whereas the dotted curves show the simplified solution with a bilinear moment-curvature relationship of Eq. (7). For the thin slabs of Fig. 8, both solutions predict the punching load for all reinforcement ratios very well. It may be noted, however, that the distance between the two solutions is larger for smaller reinforcement ratios at lower load levels. In these cases, Eq. (6) (which uses a quadrilinear moment-curvature relationship) predicts the full load-rotation relationship with good accuracy. Equation (7), with a simplified bilinear moment-curvature relationship, gives adequate but less accurate results, especially for low load levels, in which the tensile strength of concrete and tension stiffening effects are more pronounced. Both approaches correctly describe the actual rotation capacity of the slab at failure. The punching shear strength can be obtained directly by substituting Eq. (6) or (7) into Eq. (5) and solving the resulting equation.

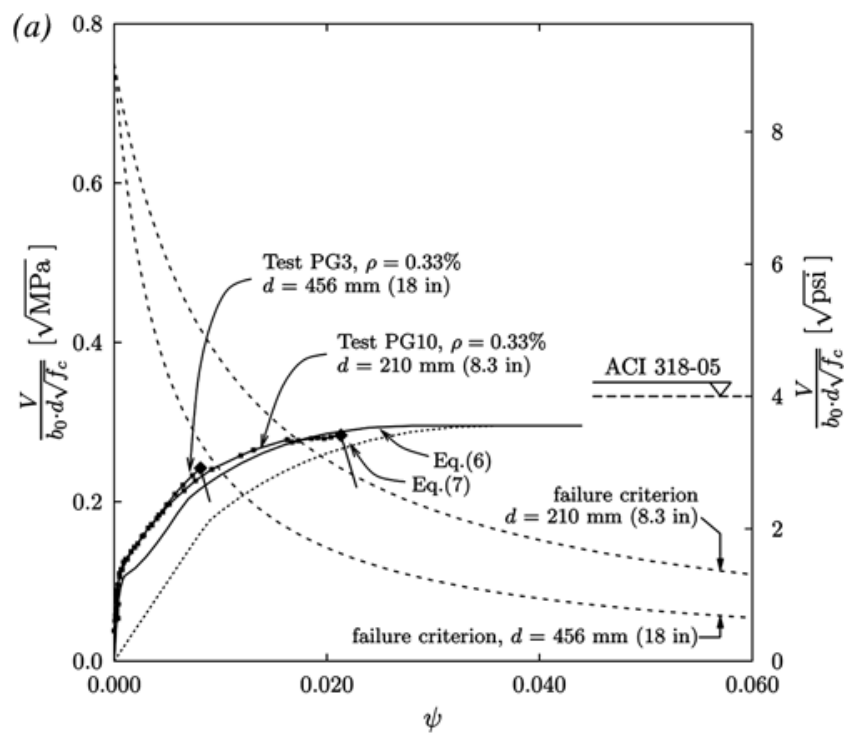

(b)
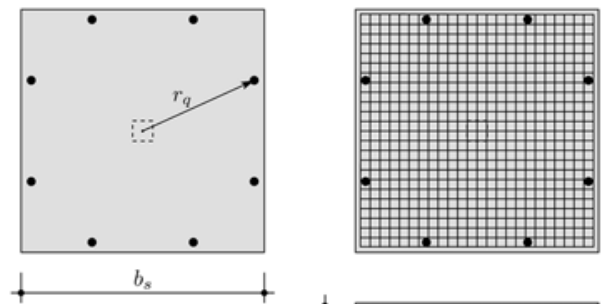

(c)

\begin{tabular}{|c|c|c|}
\cline { 2 - 3 } \multicolumn{1}{c|}{} & PG - 3 & PG - 10 \\
\hline$b_{s}[\mathrm{~mm}(\mathrm{in})]$ & $6000(236)$ & $3000(118)$ \\
\hline$b_{c}[\mathrm{~mm}(\mathrm{in})]$ & $520(20.4)$ & $260(10.2)$ \\
\hline$r_{q}[\mathrm{~mm}(\mathrm{in})]$ & $2845(112)$ & $1423(56)$ \\
\hline$d[\mathrm{~mm}(\mathrm{in})]$ & $456(17.9)$ & $210(8.26)$ \\
\hline$\rho[\%]$ & 0.33 & 0.33 \\
\hline$f_{c}[\mathrm{MPa}(\mathrm{psi})]$ & $32.4(4700)$ & $34.7(5000)$ \\
\hline$f_{y}[\mathrm{MPa}(\mathrm{ksi})]$ & $520(75.3)$ & $577(83.6)$ \\
\hline
\end{tabular}

Fig. 9-Load-rotation curves and failure criterion, comparison for Tests PG-3 and PG-10 by Guandalini and Muttoni ${ }^{13}$ : (a) analytical and experimental load-rotation curves and failure criterion according to Eq. (5); (b) geometry of specimens; and (c) geometric and mechanical parameters for each specimen.

\section{Influence of thickness of slab}

Figure 9 shows the load-rotation curves for two tests by Guandalini and Muttoni. ${ }^{13}$ These two tests are very similar, with the same reinforcement ratio $(\rho=0.33 \%)$ and the same maximum aggregate size $\left(d_{g}=16 \mathrm{~mm}\right.$ [0.63 in.]). What distinguishes them is the dimensions of the slabs: Slab PG10 is $3.0 \times 3.0 \times 0.25 \mathrm{~m}$ (118 $\times 118 \times 9.8 \mathrm{in}$.), whereas Slab PG3 is twice as large $6.0 \times 6.0 \times 0.5 \mathrm{~m}$ (236 × $236 \times 19.7$ in.). To facilitate the comparison of these two tests, the abscissa, contrary to the previous figures, shows the actual slab rotation, not the value corrected for aggregate size and size effect. In this representation, the load-rotation relationship of both slabs is nearly identical, as they are geometrically identical, but scaled 2:1. The failure criteria, however, are different due to their different thicknesses. This is why two dotted lines are shown, giving the failure criterion of Eq. (5) for each slab thickness, the upper applying to the thinner and the lower to the thicker slab. In the latter case, with a low reinforcement ratio, the difference between the two loadrotation relationships, with and without tension stiffening, becomes apparent, whereas the more accurate expression of Eq. (6) quite closely predicts the entirety of the loading curve, the simpler solution of Eq. (7) clearly underestimates the stiffness of the slab in its initial loading stages, thus leading to an underestimation of the punching shear strength. Whereas both equations give conservative estimates of the actual failure load, only Eq. (6) correctly describes all stages of the actual behavior of the thick slab with a small reinforcement ratio. Because both slabs are geometrically similar and because of size effect, the thicker slab has a lower rotation capacity and fails in a rather brittle manner, in spite of its low reinforcement ratio, whereas the thinner slab exhibits a more ductile behavior.

Figure 10 further illustrates this phenomenon by showing the load-rotation curves according to Eq. (6) for various reinforcement ratios, along with the failure criteria for various slab thicknesses. The constant value predicted by the ACI $318-05^{6}$ design equation is also shown for comparison.

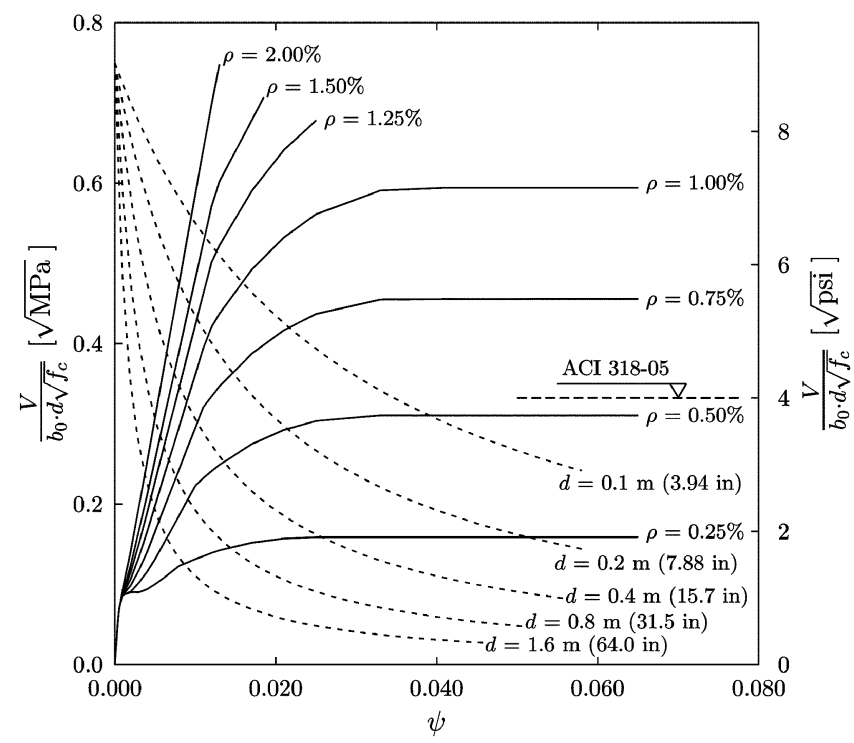

Fig. 10-Load-rotation curves and failure criteria for various reinforcement ratios and slab thicknesses $\left(\mathrm{h}=\mathrm{r}_{\mathrm{c}}=1.2 \mathrm{~d}, \mathrm{r}_{\mathrm{s}}=\right.$ $\mathrm{r}_{\mathrm{q}}=7 \mathrm{~d}, \mathrm{f}_{\mathrm{c}}=30 \mathrm{MPa}[4200 \mathrm{psi}], \mathrm{f}_{\mathrm{y}}=500 \mathrm{MPa}[71 \mathrm{ksi}]$, and $\mathrm{d}_{\mathrm{g}}=25 \mathrm{~mm}$ [1 in.]). 
For thinner slabs and larger reinforcement ratios, the mode of failure is brittle, generally at values larger than predicted by the ACI equation. For lower reinforcement ratios, but in particular for thicker slabs, the equations proposed herein predict much lower values. This is especially important for thick slabs and foundation mats that may commonly exceed a thickness of $0.4 \mathrm{~m}$ (16 in.). In such cases, even for relatively low reinforcement ratios, the failure mode is brittle and occurs at load levels clearly below those predicted by ACI, not reaching the theoretical flexural failure load.

Moe's ${ }^{19}$ design equation, which remains the basis for the current ACI design equation (Eq. (1)), does not include a term to account for the effect of the longitudinal reinforcement. It was, however, derived from an analytical expression that does, as explained by Alexander and Hawkins. ${ }^{9}$ It expresses the punching shear strength as a function of the ratio $V_{R} / V_{\text {flex }}$ (punching shear strength $V_{R}$ to the load corresponding to the bending capacity $V_{\text {flex }}$ of the slab). Using Eq. (7c), the test series by Moe ${ }^{19}$ and Elstner and Hognestad ${ }^{18}$ can be represented as in Fig. 11. From the data available at that time, Moe's ${ }^{19}$ conclusion of a linear relationship between the punching shear strength and the ratio $V_{R} / V_{\text {flex }}$ of the slab is confirmed. Shown alongside in the figure as continuous lines are the ultimate loads obtained using the proposed model. It can be observed that the level of shear at which failure occurs diminishes with increasing thickness of the slab, but the slope remains approximately the same as that observed by $\mathrm{Moe}^{19}$ on thin slabs. The size effect is very marked, especially for thick slabs. For slabs thicker than $0.4 \mathrm{~m}$ (16 in.), the ACI $318-05^{6}$ design equation overestimates the punching shear strength and does not ensure a ductile behavior.

Also shown in Fig. 11 is the effect of the bending reinforcement: increasing this reinforcement increases the punching shear capacity but simultaneously decreases the ratio of the punching load to the flexural load, which translates into smaller

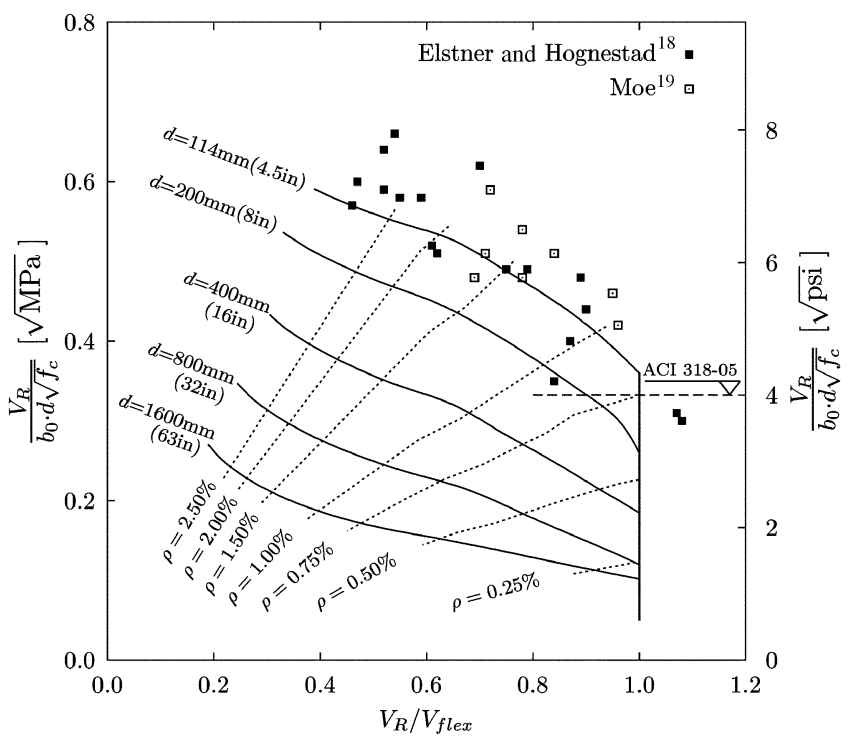

Fig. 11-Punching shear strength as function of $\mathrm{V} / \mathrm{V}_{\mathrm{flex}}$ ratio for various slab thicknesses and reinforcement ratios $\left(\mathrm{r}_{\mathrm{c}}=1.4 \mathrm{~d}, \mathrm{r}_{\mathrm{s}}=9.2 \mathrm{~d}, \mathrm{r}_{\mathrm{q}}=7.8 \mathrm{~d}, \mathrm{f}_{\mathrm{c}}=24 \mathrm{MPa}\right.$ [3400 psi], and $\mathrm{f}_{\mathrm{y}}=350 \mathrm{MPa}[50 \mathrm{ksi}]$ ); comparison with tests by Elstner and Hognestad ${ }^{18}$ and Moe ${ }^{19}\left(\mathrm{~d}=114 \mathrm{~mm}\right.$ [4.5 in.], $\mathrm{b}_{\mathrm{c}}=$ $254 \mathrm{~mm}$ [10 in.], $\mathrm{b}_{\mathrm{s}}=1830 \mathrm{~mm}$ [72 in.], $\mathrm{r}_{\mathrm{q}}=890 \mathrm{~mm}$ [35 in.], $\mathrm{f}_{\mathrm{c}}=13$ to $51 \mathrm{MPa}[1820$ to $7180 \mathrm{psi}], \mathrm{f}_{\mathrm{y}}=303$ to $482 \mathrm{MPa}$ [43.1 to $68.6 \mathrm{ksi}$ ], and $\rho=0.5$ to $7 \%$ ). rotations at failure. In such cases, the only way to ensure a ductile behavior of the slab is to include shear reinforcement.

\section{SIMPLIFIED DESIGN METHOD}

For practical purposes, the load-rotation relationship can be further simplified by assuming a parabola with a $3 / 2$ exponent for the rotation $\psi$ as a function of the ratio $V / V_{\text {flex }}$ and by assuming that the flexural strength $V_{\text {flex }}$ (refer to Eq. (7c)) is reached for a radius of the yielded zone $r_{y}$ equal to 0.75 times the radius of the isolated slab element $r_{s}$. These assumptions, together with Eq. (16), (18), and (22) from Appendix 1, lead to the following relationship

$$
\psi=1.5 \frac{r_{s}}{d} \frac{f_{y}}{E_{s}}\left(\frac{V}{V_{\text {flex }}}\right)^{3 / 2}
$$

Figure 12 shows, again for the four tests by Kinnunen and Nylander, ${ }^{8}$ the experimental load-rotation relationship along with those given by Eq. (6) and by the simplified design method of Eq. (8). Both expressions correctly predict the punching load, the simplified design equation giving slightly more conservative values.

In Table 2, the various expressions proposed in this paper, the complete solution of Eq. (6), and the simplified solution of Eq. (8) are compared on the basis of nine test series by various researchers, for a total of 87 tests. The number of tests in Table 2 is smaller than that of Table 1 because tests with different reinforcement ratios in orthogonal directions are not considered (tests by Nylander and Sundquist ${ }^{24}$ and Kinnunen et al. ${ }^{25}$ ). For tests with square columns, the radius of the column was assumed to be $r_{c}=2 b_{c} / \pi$, where $b_{c}$ is the side of the square column, leading to the same control perimeter. It should be noted that a control perimeter with rounded edges is adopted when checking the punching shear strength according to ACI $318-05^{6}$ (this is the default control perimeter according to this code, where it is also permitted a four straight-sided control perimeter, refer to Section 11.12.1.3 of ACI $\left.318-05^{6}\right)$. Similarly, square slabs are transformed into circular elements with the same flexural strength. Also

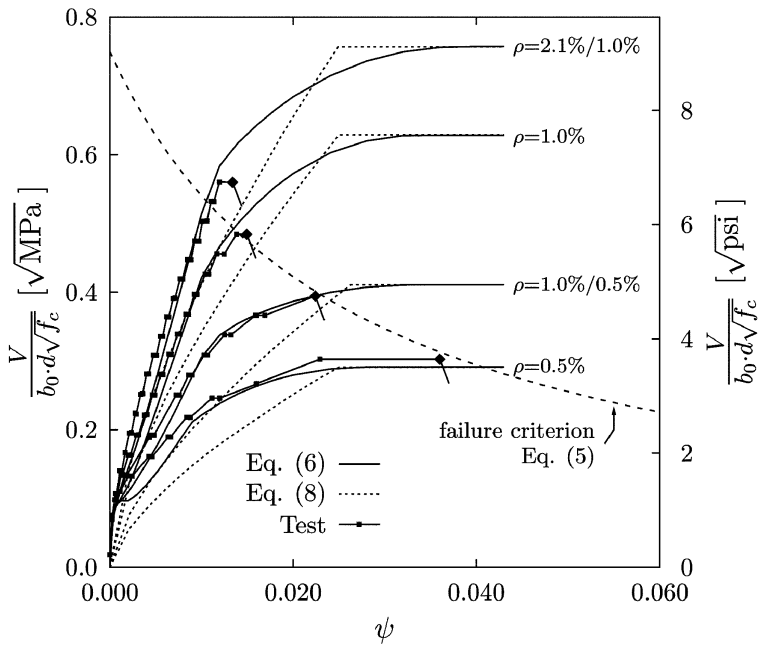

Fig. 12-Plots of load-rotation curves for tests by Kinnunen and Nylander ${ }^{8}$ (refer to Fig. 8 for geometrical and mechanical parameters) and comparison to analytical laws of Eq. (6) and (8). 
shown in Table 2 and plotted in Fig. 13 are the results from ACI $318-05^{6}$ and Eurocode $2 .^{7}$ The results predicted by the proposed formulations are excellent, with an average ratio of effective to predicted load close to unity, and a very small coefficient of variation (COV) of 0.08 , respectively, 0.09 . Also remarkable is the minimum value of the ratio $V_{\text {test }} / V_{t h}$ given in Table 2. A ratio smaller than 1.0 means that the actual strength can be lower than predicted. It is 0.86 for both proposed formulations.

Tests in which failure occurred after reaching the flexural strength of the slab are also included in the results; in this case, setting the bending strength to its theoretical value (Eq. (7c)). This is why, in Fig. 13, a series of results are agglutinated along the inclined dotted line that delimits the bending failure mode.

The results given by the simplified Eq. (7) with a bilinear load-rotation relationship, not shown in the table, are very similar to those given by the complete solution of Eq. (6). This is not surprising because the considered test series include, above all, specimens with small or moderate slab thicknesses. By comparisons, the results of ACI $318-05^{6}$ are generally much more conservative, which is to be expected from a design code, but with a much larger $\mathrm{COV}$ (0.22 with rounded critical section or 0.20 with a square-sized critical section), with the potential to actually lead to unsafe designs (the minimum value of the ratio $V_{\text {test }} / V_{\text {th }}$ for the considered tests is 0.82). Furthermore, the ratio $V_{\text {test }} / V_{\text {th }}$ strongly decreases for ACI $318-05^{6}$ with increasing value of the effective depth of the slab (refer to tests by Hassanzadeh ${ }^{22}$ and Hallgren ${ }^{10}$ in Table 2 with $d=200 \mathrm{~mm}$ [7.87 in.] or Test PG-3 by Guandalini and Muttoni ${ }^{13}$ with $d=456 \mathrm{~mm}$ [17.9 in.] in Fig. 9).

The results of Eurocode $2^{7}$ are better, with a smaller average of the ratio, and also a smaller COV (average ratio of $V_{\text {test }} / V_{\text {th }}$ equal to 1.14 and a COV of 0.12 with a minimum value of 0.86 ). It can be noted that Eurocode $2^{7}$ limits the value of the factor affecting size effect for slabs with effective depths smaller than $200 \mathrm{~mm}$ (7.87 in.) to 2.0 (refer to Eq. (3)), which allows accounting for thickness tolerance for thin slabs. If this limit is not considered, the code equation shows better agreement to test results, with an average of 1.02 and a COV of 0.09 , however, the minimum value of the ratio $V_{\text {test }} / V_{\text {th }}$ decreases to 0.79 .

\section{Size effect}

Size effect on punching shear strength was introduced initially in this paper by multiplying the slab rotation $\psi$ by its thickness $d$ in the formulation of Eq. (5). It is interesting to note that a slenderness effect (dependency on the ratio $r_{s} / d$ ) is present in the load-rotation relationship given by Eq. (8). Because the rotation according to this equation is inversely proportional to the slab thickness, if Eq. (8) is introduced into Eq. (5), the slab thickness $d$ cancels on the right-hand side of the equation. Consequently, it follows that the factor for the reduction of the strength for size effect is not a function
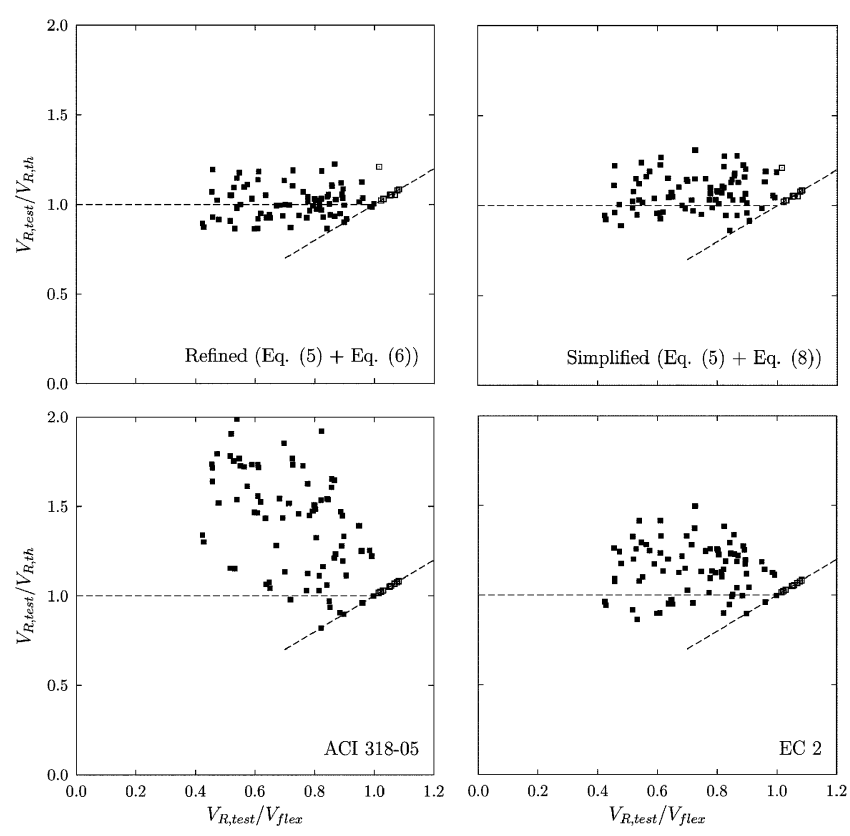

Fig. 13-Comparison of various formulations of ACI 318-05, ${ }^{6}$ Eurocode 2,' and combination of Eq. (5) and (6) and of Eq. (5) and (8) with test results shown in Fig. 5 and Table 2.

Table 2-Comparison of results of test series with predicted strength of proposed approaches and of current design codes*; average, COV, and minimum value of ratio $V_{\text {test }} / V_{t h}$

\begin{tabular}{|c|c|c|c|c|c|c|c|c|c|c|c|c|c|c|}
\hline \multirow[b]{2}{*}{ Reference (year) } & \multirow[b]{2}{*}{$d$, mm (in.) } & \multirow[b]{2}{*}{ No. } & \multicolumn{3}{|c|}{ Eq. (5) + Eq. (6) } & \multicolumn{3}{|c|}{ Eq. (5) + Eq. (8) } & \multicolumn{3}{|c|}{ ACI $318-05^{6}$} & \multicolumn{3}{|c|}{$\mathrm{EC} 2^{7}$} \\
\hline & & & Average & $\mathrm{COV}$ & Minimum & Average & $\mathrm{COV}$ & Minimum & Average & $\mathrm{COV}$ & Minimum & Average & $\mathrm{COV}$ & Minimum \\
\hline Elstner and Hognestad ${ }^{18}(1956)$ & $115(4.52)$ & 22 & 1.01 & 0.07 & 0.88 & 1.01 & 0.07 & 0.86 & 1.50 & 0.20 & 1.05 & 1.16 & 0.09 & 0.95 \\
\hline Kinnunen and Nylander ${ }^{8}(1960)$ & $122(4.80)$ & 12 & 1.02 & 0.09 & 0.86 & 1.08 & 0.08 & 0.96 & 1.45 & 0.18 & 1.03 & 1.14 & 0.13 & 0.90 \\
\hline $\operatorname{Moe}^{19}(1961)$ & $114(4.48)$ & 9 & 1.06 & 0.09 & 0.94 & 1.07 & 0.09 & 0.98 & 1.51 & 0.10 & 1.25 & 1.22 & 0.07 & 1.13 \\
\hline Schäfers ${ }^{20}(1984)$ & $\begin{array}{c}113 \text { to } 170 \\
(4.45 \text { to } 6.69)\end{array}$ & 4 & 1.02 & 0.08 & 0.93 & 1.06 & 0.10 & 0.94 & 1.41 & 0.14 & 1.16 & 1.25 & 0.05 & 1.19 \\
\hline Tolf $^{21}(1988)$ & $\begin{array}{c}98 \text { to } 200 \\
(3.86 \text { to } 7.87)\end{array}$ & 8 & 0.98 & 0.10 & 0.87 & 1.06 & 0.10 & 0.92 & 1.33 & 0.21 & 0.98 & 1.11 & 0.14 & 0.94 \\
\hline Hassanzadeh $^{22}$ (1996) & $200(7.87)$ & 3 & 0.97 & 0.09 & 0.87 & 1.04 & 0.08 & 0.95 & 1.10 & 0.06 & 1.03 & 1.03 & 0.14 & 0.86 \\
\hline Hallgren ${ }^{10}(1996)$ & $199(7.83)$ & 7 & 0.94 & 0.04 & 0.90 & 1.06 & 0.07 & 0.96 & 1.05 & 0.09 & 0.90 & 0.96 & 0.05 & 0.90 \\
\hline Ramdane $^{24}$ (1996) & $98(3.86)$ & 12 & 1.07 & 0.08 & 0.94 & 1.16 & 0.08 & 1.03 & 1.43 & 0.23 & 0.91 & 1.22 & 0.12 & 1.00 \\
\hline Guandalini and Muttoni $^{13}$ (2004) & $\begin{array}{c}96 \text { to } 464 \\
(3.78 \text { to } 18.2)\end{array}$ & 10 & 1.07 & 0.08 & 0.95 & 1.14 & 0.08 & 1.02 & 1.16 & 0.24 & 0.82 & 1.04 & 0.09 & 0.90 \\
\hline$\Sigma$ & & 87 & 1.02 & 0.08 & 0.86 & 1.07 & 0.09 & 0.86 & 1.37 & 0.22 & 0.82 & 1.14 & 0.12 & 0.86 \\
\hline
\end{tabular}

${ }^{*}$ Tests with different bending reinforcement ratios along orthogonal directions not included.

Note: $\mathrm{COV}=$ coefficient of variation. 
of the slab thickness, but rather of the span, represented in Eq. (8) by the radius $r_{s}$ of the isolated slab element.

\section{CODE-LIKE FORMULATION}

In 2003, Muttoni ${ }^{17}$ proposed a similar relationship for the failure criterion for punching shear of flat slab systems assuming that $r_{s}=0.22 L$, where $L$ is the span of the slab, and that the flexural capacity of the slab is $V_{\text {flex }} \cong 8 m_{R d}$ (where $m_{R d}$ is the flexural capacity of the slab in the column region reduced by the strength reduction factor). The resulting loadrotation relationship is thus

$$
\psi=0.33 \frac{L}{d} \frac{f_{y}}{E_{s}}\left(\frac{V_{d}}{8 m_{R d}}\right)^{3 / 2}
$$

where $V_{d}$ is the factored shear force. Here again, the rotation is slenderness-dependent and thus it is inversely proportional to the thickness of the slab, with the consequence that the size effect factor of Eq. (5) is again a function of the span $L$ of the slab and not of its thickness. Equation (9) is formulated for intermediate columns; for edge columns, the constant 8 is to be replaced by 4 and for corner columns by 2 .

Equation (5), in a slightly rearranged form and to reach a target fractile of 5\%, including a model factor to cover some irregularities in the spans and in disposition of the loading, has been introduced in the Swiss Code for structural concrete SIA $262^{27}$ as

$$
\left.\frac{V_{R d}}{b_{0} d \sqrt{f_{c}^{\prime}}}=\frac{2}{3 \gamma_{c}} \frac{1}{1+20 \frac{\psi d}{d_{g 0}+d_{g}}} \text { (SI units: } \mathrm{N}, \mathrm{mm}\right)
$$

where $\gamma_{c}$ is the partial safety factor of concrete $\left(\gamma_{c}=1.5\right)$ or

$$
\frac{V_{R d}}{b_{0} d \sqrt{f_{c}^{\prime}}}=\phi \frac{8}{1+20 \frac{\psi d}{d_{g 0}+d_{g}}} \text { (U.S. customary units: psi, in.) }
$$

where $\phi$ is the strength reduction factor for punching $(\phi=0.75)$.

\section{Design approach}

It is possible to combine Eq. (9) describing the loaddeflection behavior of the slab element with the failure criterion of Eq. (10) into a single design formula. The exact

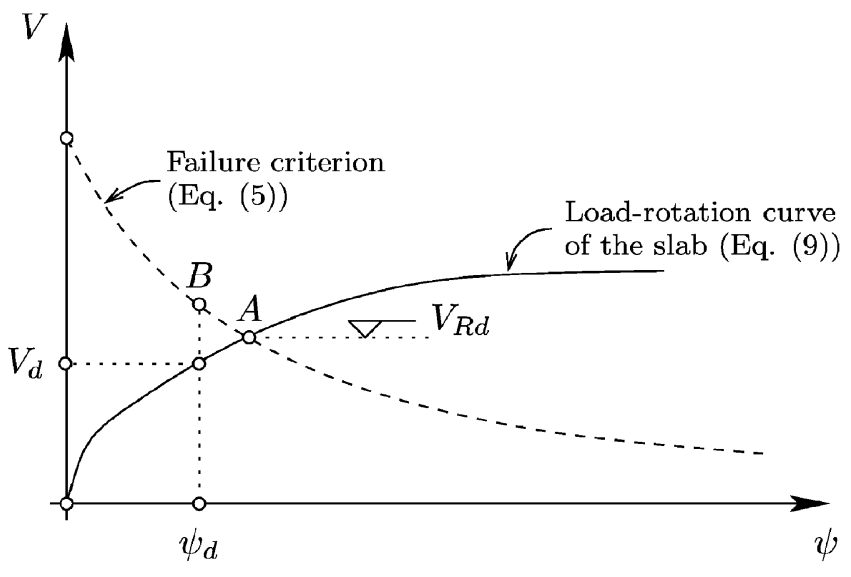

Fig. 14-Design procedure to check punching strength of slab. punching strength (Point A in Fig. 14) is then obtained by setting $V_{R d}$ equal to $V_{d}$ and iteratively solving the resulting equation. Requiring an iterative calculation even for the simplest cases, this formulation would not be very useful in practice. Instead, a simple design check can be performed calculating the slab rotation $\psi_{d}$ corresponding to the factored shear force $V_{d}$ using Eq. (9). From that value, the corresponding punching shear strength of the slab (Point B of Fig. 14) is found by applying Eq. (10). If the strength obtained from Eq. (10) is larger than the design load $V_{d}$, the design is safe and conservative. If, on the contrary, it is insufficient, the flexural reinforcement, the column size, or the slab thickness has to be increased.

\section{Parametric study and comparison to test results}

Figure 15 demonstrates the ability of the proposed formulation to investigate various aspects of the phenomenon of punching shear. As already known, an increase in the bending reinforcement leads to an increase in the punching shear capacity (Fig. 15(a)). This effect is not considered in the ACI $318-05^{6}$ formulation, but is included in Eurocode $2^{7}$ and the proposed formulation (where an increase in the bending reinforcement reduces the slab rotation $\psi$ ).

The effect of the size of the column relative to the thickness of the slab is illustrated in Fig. 15(b). This effect is considered by ACI, but only for large values of the ratio $b_{0} / d$. The proposed formulation, again, correctly describes this effect for the available test results, as does the formulation of Eurocode $2,^{7}$ which handles it by working with a control perimeter located at $2 d$ from the column face instead of $d / 2$ for ACI and the present paper.

Figure 15(c) shows the effect of the effective slab thickness on the punching strength. The few available tests point toward a strong decrease for very thick slabs, which is correctly described by the proposed model and Eurocode $2^{7}$ but ignored by ACI.

Concerning the effect of concrete strength on punching shear, Eurocode $2^{7}$ and the proposed formulation give consistently good results, as shown in Fig. 15(d).

The effect of the type of steel used and of its yield stress $f_{y}$ has been the object of only limited investigations, mostly by Moe. ${ }^{19}$ This effect is not very pronounced, but a slight increase with increasing yield stress is predicted by the proposed formulation.

The span-depth ratio of the slab, represented by the ratio $r_{s} / d$ for isolated slab elements also has an effect on the punching shear strength, according to the proposed formulation. This effect is considered neither by ACI $318-05^{6}$ nor by Eurocode 2 . $^{7}$ Further research should be devoted to investigate this aspect, as the punching strength of very slender slabs appears to be lower than expected, and no tests with significant thickness are currently available.

\section{SUMMARY AND CONCLUSIONS}

Design rules for punching shear present in design codes are generally based on experimental results performed on isolated slab elements representing the part of the slab close to the column. Most tests have been performed on relatively thin slabs, typically 0.1 to $0.2 \mathrm{~m}$ (4 to 8 in.). The test results are nonetheless commonly extrapolated to design flat slabs with a thickness typically 2 to 3 times larger, and even for foundation mats with thicknesses 10 to 20 times larger.

The present paper proposes a mechanical model based on the critical shear crack theory, explaining punching behavior 

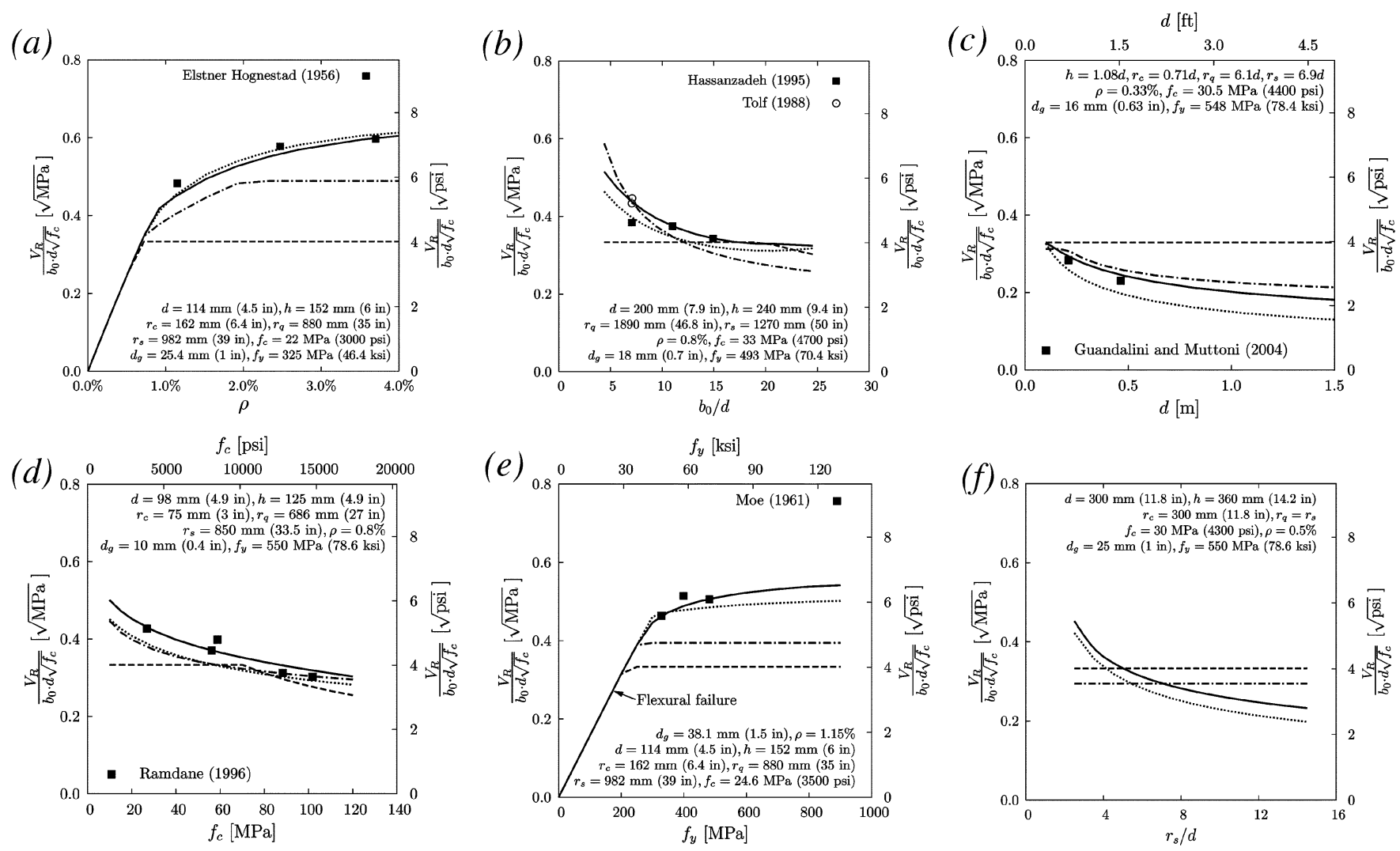

ACI 318-05

Refined method Eq.(5) + Eq.(6)

EC 2

Simplified method Eq.(5) + Eq.(8)

Fig. 15-Comparison of punching shear strength according to ACI 318-05, ${ }^{6}$ Eurocode $2,{ }^{7}$ and the refined (Eq. (5) and (6)) and simplified (Eq. (5) and (8)) methods proposed in this paper with various test results showing influence of: (a) reinforcement ratio (tests by Elstner and Hognestad ${ }^{18}$ ); (b) punching shear perimeter (tests by Hassanzadeh ${ }^{22}$ and Tolf ${ }^{21}$ ); (c) effective depth of slab (tests by Guandalini and Muttoni ${ }^{13}$ ); (d) concrete strength (tests by Ramdane ${ }^{23}$ ); (e) yield strength of steel (tests by $\left.M o e^{19}\right)$; and (f) slenderness of slab.

of flat slabs without shear reinforcement and correctly accounting for size effect. A failure criterion is derived on its basis, which suitably describes the role of the many geometric and mechanical parameters involved in punching shear. The main conclusions of this paper are:

1. According to the proposed failure criterion, the punching strength is a function of the opening of a critical shear crack in the slab. Its influence is assumed to be proportional to the product of the slab rotation times the slab thickness and corrected by a factor to account for the maximum diameter of the aggregate;

2. This failure criterion simultaneously determines the punching load and the rotation capacity of the slab, and thus of its ductility;

3. The punching load can be determined by applying the failure criterion and a load-rotation relationship obtained from a nonlinear analysis of the slab in bending. For axisymmetric cases, an analytical formulation derived on the basis of a nonlinear moment-curvature diagram is given;

4. A simplified bilinear (elasto-plastic) moment-curvature relationship can also be applied to accurately estimate the punching load. The use of a more sophisticated momentcurvature relationship is only required for thick slabs with low reinforcement ratios, in which it is necessary to precisely account for the effects of the tensile strength of concrete and of tension stiffening;

5. A simplified analytical formulation of the load-rotation relationship, as it is used in the current Swiss design code for concrete structures, also gives a good estimate of the punching load;

6. The article proposes a method to calculate the punching strength as a function of the effective depth of the slab, the size of the column, the flexural reinforcement ratio, the yield strength of the reinforcing steel, the concrete strength, the maximum aggregate size, and the span-depth ratio of the slab. This method gives very good results when compared with a series of 87 test results, with a COV of the ratio $V_{\text {test }} / V_{t h}$ of $8 \%$;

7. Size effect on the punching shear strength is accounted in the failure criterion of the critical shear crack theory. This effect, in combination with the slenderness effect on the load-rotation relationship proposed in this paper, can be formulated as a function of the span of the slab;

8. ACI $318-05^{6}$ does not only exhibit a very large COV when compared with test results (22\%), but it does not include important effects, which leads to unsafe designs in particular for thick and/or slender slabs with low reinforcement ratios; 
9. Eurocode $2^{7}$ has a better $\mathrm{COV}$ when compared with test results $(12 \%)$, but it also can predict unconservative values for slender slabs;

10. Even if tests on thin slabs have exhibited some level of ductility for low reinforcement ratios, the behavior is quite brittle for thicker slabs; and

11. For thick slabs, the only solution to reach a satisfactory level of ductility is to place punching shear reinforcement.

\section{ACKNOWLEDGMENTS}

The work presented in this paper was funded by the Association of the Swiss Cement Industry (cemsuisse) and by the Swisscode project of the Swiss Society of Engineers and Architects (SIA). The author is appreciative of the support received.

\section{REFERENCES}

1. Gasparini, D. A., "Contributions of C. A. P. Turner to Development of Reinforced Concrete Flat Slabs 1905-1909," Journal of Structural Engineering, ASCE, V. 128, No. 10, 2002, pp. 1243-1252.

2. Fürst, A., and Marti, P., "Robert Maillart's Design Approach for Flat Slabs," Journal of Structural Engineering, ASCE, V. 123, No. 8, 1997, pp. $1102-1110$.

3. Silfwerbrand, J., and Hassanzadeh, G., eds., "International Workshop on Punching Shear Capacity of RC Slabs," Royal Institute of Technology, Stockholm, Sweden, 2000, 527 pp.

4. FIB, "Punching of Structural Concrete Slabs," fib Bulletin 12, Lausanne, Switzerland, 2001, $307 \mathrm{pp}$.

5. Polak, M. A., ed., Punching Shear in Reinforced Concrete Slabs, SP-232, American Concrete Institute, Farmington Hills, MI, 2005, 302 pp.

6. ACI Committee 318, "Building Code Requirements for Structural Concrete (ACI 318-05) and Commentary (318R-05)," American Concrete Institute, Farmington Hills, MI, 2005, 430 pp.

7. Eurocode 2, "Design of Concrete Structures-Part 1-1: General Rules and Rules for Buildings," CEN, EN 1992-1-1, Brussels, Belgium, 2004, $225 \mathrm{pp}$.

8. Kinnunen, S., and Nylander, H., "Punching of Concrete Slabs Without Shear Reinforcement," Transactions of the Royal Institute of Technology, No. 158, Stockholm, Sweden, 1960, 112 pp.

9. Alexander, S. D. B., and Hawkins, N. M., A Design Perspective on Punching Shear, SP-232, M. A. Polak, ed., American Concrete Institute, Farmington Hills, MI, 2005, pp. 97-108.

10. Hallgren, M., "Punching Shear Capacity of Reinforced High Strength Concrete Slabs," doctoral thesis, Royal Institute of Technology, Stockholm, Sweden, 1996, 206 pp.

11. Broms, C. E., Concrete Flat Slabs and Footings: Design Method for Punching and Detailing for Ductility, Royal Institute of Technology, Stockholm, Sweden, 2006, 114 pp.
12. Muttoni, A., and Schwartz, J., "Behaviour of Beams and Punching in Slabs without Shear Reinforcement," IABSE Colloquium, V. 62, Zurich, Switzerland, 1991, pp. 703-708.

13. Guandalini, S., and Muttoni, A., "Symmetric Punching Tests on Reinforced Concrete Slabs without Shear Reinforcement," Test report, EPFL, Lausanne, Switzerland, 2004, 78 pp. (in French)

14. Bollinger, K., "Load-Carrying Behaviour and Reinforcement of Axisymmetrically Loaded Reinforced Concrete Plates," doctoral thesis, Abteilung Bauwesen der Universität Dortmund, Dortmund, Germany, 1985, 262 pp. (in German)

15. Walraven, J. C., "Fundamental Analysis of Aggregate Interlock," Journal of Structural Engineering, ASCE, V. 107, No. 11, 1981, pp. 2245-2270.

16. Vecchio, F. J., and Collins, M. P., "The Modified Compression-Field Theory for Reinforced Concrete Elements Subjected to Shear," ACI Journal, Proceedings V. 83, No. 2, Mar-Apr. 1986, pp. 219-231.

17. Muttoni, A., "Shear and Punching Strength of Slabs without Shear Reinforcement," Beton-und Stahlbetonbau, V. 98, No. 2, Berlin, Germany, 2003, pp. 74-84. (in German)

18. Elstner, R. C., and Hognestad, E., "Shearing Strength of Reinforced Concrete Slabs," ACI Journal, Proceedings V. 53, No. 2, Feb. 1956, pp. 29-58.

19. Moe, J., "Shearing Strength of Reinforced Concrete Slabs and Footings under Concentrated Loads," V. D47, PCA, IL, 1961, 135 pp.

20. Schäfers, U., "Construction, Dimensioning and Safety with Respect to Punching Shear of Reinforced Concrete Flat Plates in the Vicinity of Internal Columns," Deutscher Ausschuss für Stahlbeton, No. 357, Berlin, Germany, 1984, 83 pp. (in German)

21. Tolf, P., "Influence of the Slab Thickness on the Strength of Concrete Slabs at Punching: Tests with Circular Slabs," No. 146, Royal Institute of Technology, Stockholm, Sweden, 1988, 64 pp. (in Swedish)

22. Hassanzadeh, G., "Strengthening of Bridge Slabs with Respect to Punching: Test Results," Report 41, Royal Institute of Technology, Stockholm, Sweden, 1996, 134 pp. (in Swedish)

23. Ramdane, K.-E., "Punching Shear of High Performance Concrete Slabs," Utilization of High-Strength/High Performance Concrete, Proceedings of the Fourth International Symposium, V. 3, Paris, France, 1996, pp. 1015-1026.

24. Nylander, H., and Sundquist, H., "Punching of Bridge Slabs with Non-Prestressed Reinforcement on Columns," No. 104, Royal Institute of Technology, Stockholm, Sweden, 1972, 64 pp. (in Swedish)

25. Kinnunen, S.; Nylander, H.; and Tolf, P., "Influence of the Slab Thickness on the Strength of Concrete Slabs at Punching: Tests with Rectangular Slabs," Test Report, Royal Institute of Technology, No. 137, Stockholm, Sweden, 1980, 73 pp. (in Swedish)

26. Guandalini, S., "Symmetric Punching in R/C Slabs," doctoral thesis, No. 3380, EPFL, Lausanne, Switzerland, 2005, 289 pp. (in French)

27. SIA, "262 Code for Concrete Structures," Swiss Society of Engineers and Architects, Zurich, Switzerland, 2003, 94 pp. 
2 In this appendix, a load-rotation relationship for an isolated slab element is derived based on the

3 assumption that the deflected shape of the isolated slab element is conical outside the critical shear

4 crack. The curvature in tangential direction (Fig. 6f) is thus:

$5 \quad \chi_{t}=-\frac{\psi}{r}$ for $r>r_{0}$

6 Inside the critical shear crack, it may be assumed that the curvatures in both directions are constant

7 and equal (Figs 6d,f), so that the deflected shape is spherical :

$8 \quad \chi_{r}=\chi_{t}=-\frac{\psi}{r_{0}}$ for $r \leq r_{0}$

9 With these curvatures, the internal forces described in Figs $6 b, c$ can be calculated according to the

10 quadrilinear moment-curvature relationship shown in Fig. 7. This relationship is characterized by

11 the stiffnesses $E I_{0}$ before and $E I_{1}$ after cracking, the cracking moment $m_{c r}$, the moment capacity $m_{R}$

12 and the tension stiffening effect $\chi_{T S}$. Neglecting the effect of reinforcement before cracking, these

13 terms can be obtained as:

$14 \quad m_{c r}=\frac{f_{c t} \cdot h^{2}}{6}$

$15 \quad E I_{0}=\frac{E_{c} \cdot h^{3}}{12}$

$16-\chi_{c r}=\frac{m_{c r}}{E I_{0}}=\frac{2 \cdot f_{c t}}{h \cdot E_{c}}$

17 Assuming a linear-elastic behaviour of steel and concrete after cracking, it follows:

$18 \quad E I_{1}=\rho \cdot \beta \cdot E_{s} \cdot d^{3} \cdot\left(1-\frac{c}{d}\right) \cdot\left(1-\frac{c}{3 d}\right)$

19 where $c$ is the depth of the compression zone:

$20 \quad c=\rho \cdot \beta \cdot \frac{E_{s}}{E_{c}} \cdot d \cdot\left(\sqrt{1+\frac{2 \cdot E_{c}}{\rho \cdot \beta \cdot E_{s}}}-1\right)$ 
1 and $\beta$ is an efficiency factor that accounts for the orthogonal layout of the reinforcement and the

2 reduction in the ratio between the torsion and bending stiffness of the slab after cracking. It should

3 be noted that this factor affects the stiffness of the member but not the flexural strength of the

4 member. While the developments above were made for a layout with a polar symmetry

5 (reinforcement placed in radial and tangential directions), reinforcement is usually placed

6 orthogonally in the slab. For these cases, a good agreement to test data is obtained assuming

$7 \quad \beta=0.6$.

8 Assuming a perfectly plastic behaviour of the reinforcement after yielding, a rectangular stress

9 block for concrete in the compression zone and neglecting compression reinforcement, the moment

10 capacity $m_{R}$ of the section is then:

$11 \quad m_{R}=\rho \cdot f_{y} \cdot d^{2} \cdot\left(1-\frac{\rho \cdot f_{y}}{2 \cdot f_{c}}\right)$

12 The decrease in curvature caused by tension stiffening can be approximated by the constant

13 contribution $\chi_{T S}$ :

$14 \quad \chi_{T S}=\frac{f_{c t}}{\rho \cdot \beta \cdot E_{s}} \cdot \frac{1}{6 \cdot h}$

15 which corresponds approximately to $0.5 \cdot m_{c r} / E I_{1}$.

16 The curvatures $\chi_{1}$ at the beginning of the stabilized cracked regime and $\chi_{y}$ at yielding are thus:

$17-\chi_{1}=\frac{m_{c r}}{E I_{1}}-\chi_{T S}$

18 and

$19-\chi_{y}=\frac{m_{R}}{E I_{1}}-\chi_{T S}$

20 The four segments of the assumed moment-curvature relationship correspond to the four regions of

21 the slab shown in Figs $6 \mathrm{f}, \mathrm{g}$. The radii delimiting these zones may be determined by substituting

22 Eqs (15), (20) and (21) into Eq. (11), as follows:

23 Zone within which the reinforcement is yielding, plastic radius $r_{y}$ : 
$1 \quad r_{y}=-\frac{\psi}{\chi_{y}}=\frac{\psi}{\frac{m_{R}}{E I_{1}}-\chi_{T S}} \leq r_{s}$

2 Zone in which cracking is stabilized, radius $r_{1}$ :

$3 \quad r_{1}=-\frac{\psi}{\chi_{1}}=\frac{\psi}{\frac{m_{c r}}{E I_{1}}-\chi_{T S}} \leq r_{s}$

4 and zone up to which the concrete is cracked, cracking radius $r_{c r}$ :

$5 \quad r_{c r}=-\frac{\psi}{\chi_{c r}}=\frac{\psi \cdot E I_{0}}{m_{c r}} \leq r_{s}$

6 The equilibrium equation of the slab portion shown in Fig. 6c is:

$7 \quad V \cdot \frac{\Delta \varphi}{2 \pi} \cdot\left(r_{q}-r_{c}\right)=-m_{r} \cdot \Delta \varphi \cdot r_{0}-\Delta \varphi \cdot \int_{r_{0}}^{r_{s}} m_{\varphi} \cdot d r$

8 where $m_{r}$ is the radial moment at $r=r_{0}$ calculated according to Fig. 7 with the curvature given by

9 Eq. (12). It follows that:

$10 V=\frac{2 \pi}{r_{q}-r_{c}} \cdot\left(\begin{array}{l}-m_{r} \cdot r_{0}+m_{R} \cdot\left\langle r_{y}-r_{0}\right\rangle+E I_{1} \cdot \psi \cdot\left\langle\ln \left(r_{1}\right)-\ln \left(r_{y}\right)\right\rangle+ \\ E I_{1} \cdot \chi_{T S} \cdot\left\langle r_{1}-r_{y}\right\rangle+m_{c r} \cdot\left\langle r_{c r}-r_{1}\right\rangle+E I_{0} \cdot \psi \cdot\left\langle\ln \left(r_{s}\right)-\ln \left(r_{c r}\right)\right\rangle\end{array}\right)$

11 where the operator $\langle x\rangle$ is $x$ for $x \geq 0$ and 0 for $x<0$

12

14 The following symbols are used in the paper:

$15 E_{c}=$ modulus of elasticity of concrete (assumed $E_{c}=10^{\prime} 000 \cdot f_{c}^{1 / 3}[\mathrm{MPa}]$,

$$
\left.E_{c}=276^{\prime} 000 \cdot f_{c}^{1 / 3}[\mathrm{psi}]\right)
$$

$17 E_{s}=$ modulus of elasticity of reinforcement

$18 E I_{0}=$ flexural stiffness before cracking

$19 E I_{1}=$ tangential flexural stiffness after cracking

$20 L=$ main span of a slab system 


\begin{tabular}{|c|c|c|c|}
\hline 1 & $V$ & $=$ & shear force \\
\hline 2 & $V_{d}$ & $=$ & factored shear force \\
\hline 3 & $V_{\text {flex }}$ & $=$ & shear force associated with flexural capacity of the slab \\
\hline 4 & $V_{R}$ & $=$ & nominal punching shear strength \\
\hline 5 & $V_{R d}$ & $=$ & design punching shear strength \\
\hline 6 & $V_{\text {test }}$ & $=$ & experimental punching shear strength \\
\hline 7 & $V_{t h}$ & $=$ & theoretical punching shear strength \\
\hline 8 & $b_{0}$ & $=$ & perimeter of the critical section for punching shear \\
\hline 9 & $b_{c}$ & $=$ & side length of a square column \\
\hline 10 & $b_{s}$ & $=$ & side length of a square isolated slab element \\
\hline 11 & $c$ & $=$ & distance from extreme compression fibre to neutral axis \\
\hline 12 & $d$ & $=$ & distance from extreme compression fibre to the centroid of the longitudinal \\
\hline 3 & & & tensile reinforcement \\
\hline
\end{tabular}

$14 d_{b}=$ diameter of a reinforcement bar

$15 d_{g}=$ maximum diameter of the aggregate

$16 d_{g 0}=\quad$ reference aggregate size $(16 \mathrm{~mm}(0.63 \mathrm{in}))$

$17 f_{c}=$ average compressive strength of concrete (cylinder)

$18 f_{c}^{\prime}=$ specified compressive strength of concrete (cylinder)

$19 f_{c t}=$ tensile strength of concrete (assumed $f_{c t}=0.3 \cdot f_{c}^{2 / 3}[\mathrm{MPa}], f_{c t}=1.6 \cdot f_{c}^{2 / 3}[\mathrm{psi}]$ )

$20 f_{y}=\quad$ yield strength of reinforcement

$21 h=$ slab thickness

$22 m_{c r}=\quad$ cracking moment per unit width

$23 m_{r}=\quad$ radial moment per unit width

$24 m_{t}=$ tangential moment per unit width

$25 m_{R}=$ nominal moment capacity per unit width

$26 m_{R d}=$ design moment capacity per unit width 


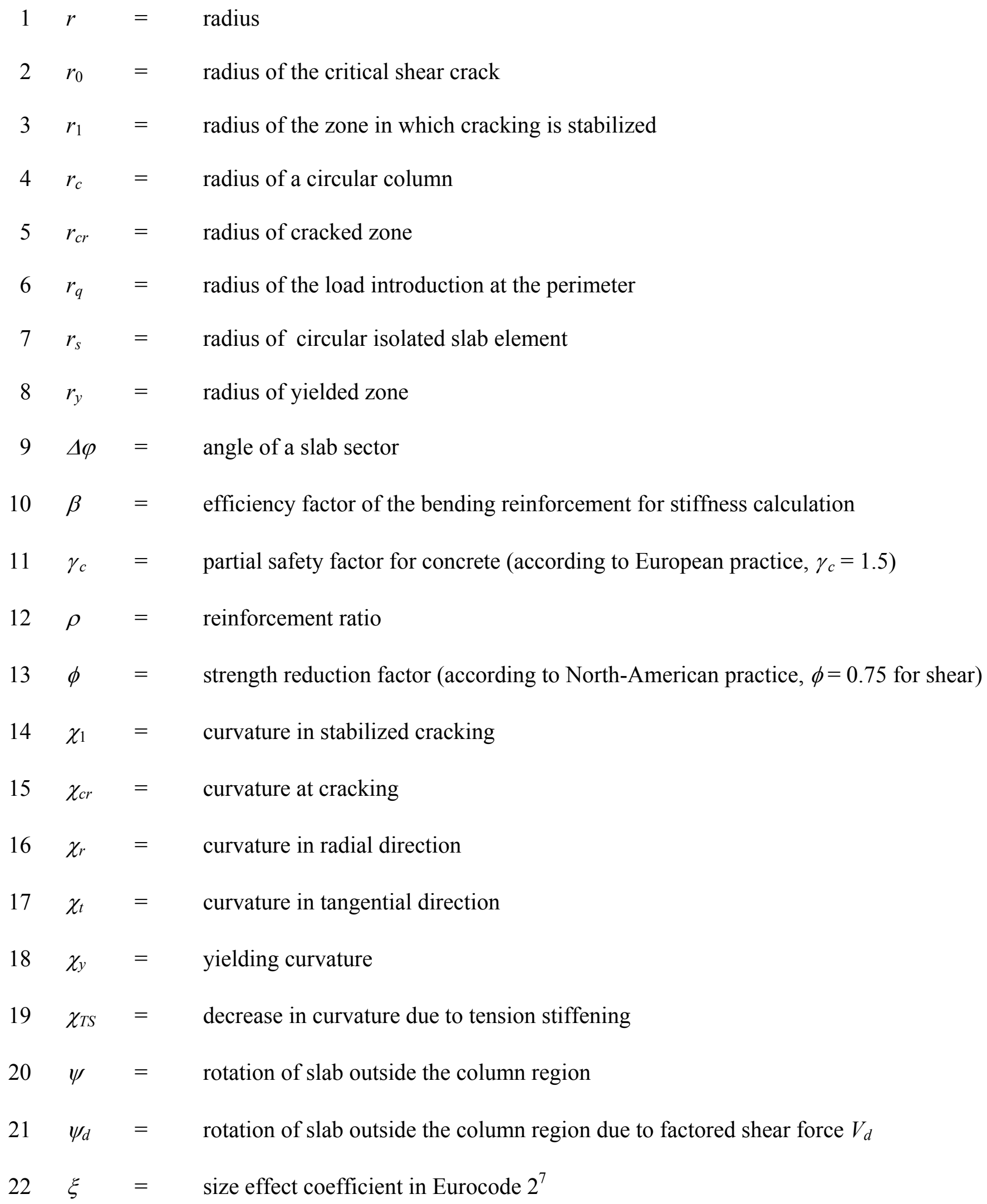

